\title{
Article \\ Phenothiazinium Photosensitizers Associated with Silver Nanoparticles in Enhancement of Antimicrobial Photodynamic Therapy
}

\author{
Glaucia Rigotto Caruso ${ }^{1}$, Ludmilla Tonani ${ }^{1}$, Priscyla Daniely Marcato ${ }^{2}$ and Marcia Regina von Zeska Kress ${ }^{1, *}$ (i) \\ 1 Department of Clinical Analysis, Toxicology and Food Sciences, School of Pharmaceutical Sciences of \\ Ribeirao Preto, University of Sao Paulo, Ribeirao Preto 15040-903, SP, Brazil; g_rigotto@hotmail.com (G.R.C.); \\ ludmilla@fcfrp.usp.br (L.T.) \\ 2 Department of Pharmaceutical Sciences, School of Pharmaceutical Sciences of Ribeirao Preto, \\ University of Sao Paulo, Ribeirao Preto 15040-903, SP, Brazil; pmarcato@fcfrp.usp.br \\ * Correspondence: kress@fcfrp.usp.br
}

check for updates

Citation: Rigotto Caruso, G.; Tonani, L.; Marcato, P.D.; von Zeska Kress, M.R. Phenothiazinium

Photosensitizers Associated with Silver Nanoparticles in Enhancement of Antimicrobial Photodynamic Therapy. Antibiotics 2021, 10, 569. https://doi.org/10.3390/ antibiotics10050569

Academic Editor: Kristjan Plaetzer

Received: 30 March 2021

Accepted: 1 May 2021

Published: 12 May 2021

Publisher's Note: MDPI stays neutral with regard to jurisdictional claims in published maps and institutional affiliations.

Copyright: (c) 2021 by the authors. Licensee MDPI, Basel, Switzerland. This article is an open access article distributed under the terms and conditions of the Creative Commons Attribution (CC BY) license (https:// creativecommons.org/licenses/by/ $4.0 /)$.

\begin{abstract}
Antimicrobial photodynamic therapy (APDT) and silver nanoparticles (AgNPs) are known as promising alternatives for the control of microorganisms. This study aims to evaluate the antifungal activity of APDT, particularly by using the association of low concentrations of phenothiazinium photosensitizers (PS) methylene blue (MB), new methylene blue $\mathrm{N}$ (NMBN), and new methylene blue N Zinc (NMBN-Zn) in association with biosynthesized AgNPs. The AgNPs were characterized by UV-Vis spectrophotometry, transmission electron microscopy, and the dynamic light scattering method. The minimum inhibitory concentration of compounds in APDT against Candida albicans and Fusarium keratoplasticum was obtained and the Fractional Inhibitory Concentration Index determined the antifungal effect. The toxicity of compounds and associations in APDT were evaluated in Galleria mellonella. The AgNPs presented a surface plasmon band peak at $420 \mathrm{~nm}$, hydrodynamic diameter of $86.72 \mathrm{~nm}$, and zeta potential of $-28.6 \mathrm{mV}$. AgNPs-PS showed a wider and displaced plasmon band peak due to PS ligands on the surface and decreased zeta potential. AgNPs-NMBN and AgNPs-NMBN-Zn associations presented synergistic effect in APDT with $15 \mathrm{~J} \mathrm{~cm}^{-2}$ against both fungi and did not show toxicity to G. mellonella. Hence, the enhancement of antifungal activity with low concentrations of compounds and absence of toxicity makes APDT with AgNPs-PS a promising therapeutic alternative for fungal infections.
\end{abstract}

Keywords: antimicrobial photodynamic therapy; phenothiazinium; silver nanoparticles; Candida albicans; Fusarium keratoplasticum

\section{Introduction}

Fungal diseases are globally and gradually on the rise. The indiscriminate and prolonged use of antifungal agents, inappropriate prescription, and interruption of antimicrobial treatment results in the growing increase in drug-resistant microorganisms, including the development of multidrug-resistant strains capable of aggravating patients' conditions [1-3]. The emergence of resistance to commercial antifungals generated the need to study therapeutic alternatives that are low-cost, efficient, and non-toxic to the environment and humans [4]. Thus, antimicrobial photodynamic therapy (APDT) is considered an interesting alternative for the control of pathogenic fungal agents [5,6]. The efficiency of APDT is influenced by factors such as light, type of photosensitizer (PS), selectivity, and production of reactive oxygen species (ROS). Moreover, an amount of PS molecules in an excited triplet state is required for the production of ROS and the consequent inactivation of microorganisms [7,8]. One of the great challenges in APDT is to correctly address the photosensitizers (PS) to increase the effectiveness of APDT using the lowest concentration of PS, the shortest time of light exposure, and light in the therapeutic window [8]. Silver 
nanoparticles (AgNPs) have shown to be efficient when complexed with photosensitizers, by addressing them correctly and improving the efficiency of APDT [9]. They play an important role in the biomedical field as vehicles for drug delivery, bioimaging, and due to their antimicrobial effect. Their potential is used against multi-resistant bacteria and fungi that may cause serious infection in humans, animals, and plants. AgNPs present unique physical, chemical, and biological characteristics such as resistance, optical properties, high reactivity, and specific interactions with biomolecules and microorganisms [10,11]. The biological method uses living systems capable of producing AgNPs in a clean, non-toxic, and sustainable way. Bacteria, algae, yeasts, and fungi have a great potential to reduce metal ions, so they can agglomerate atoms and synthesize eco-friendly nanoparticles [12].

The limitation of available antifungal drugs makes it crucial to find alternative therapies for fungal infections. Therefore, the objective of the present study is to evaluate the antifungal activity effect of APDT against the yeast fungus $C$. albicans and the filamentous fungus $F$. keratoplasticum particularly by using low concentrations of phenothiazinium photosensitizers (PS) methylene blue (MB), new methylene blue N (NMBN), and new methylene blue N Zinc (NMBN-Zn) in association with biosynthesized AgNPs. The association of PS and AgNPs in APDT was chosen hypothesizing that a synergistic effect against such pathogens might be produced.

\section{Results}

\subsection{Biosynthesis and Characterization of Silver Nanoparticles}

The extracellular biosynthesis of AgNPs was carried out and the formation of AgNPs was monitored by a visual color change of the reaction mixture, as a result of the surface plasmon resonance phenomenon. The color of the reaction mixture began to change on the third day and had changed from slight yellow to brown within 15 days of reaction (Figure 1a). The gradual biosynthesis of AgNPs was confirmed by UV-Vis spectral scanning at $200-800 \mathrm{~nm}$. An increase in plasmon band absorbance was observed at around $420 \mathrm{~nm}$ (Figure 1b).

The hydrodynamic diameter of AgNPs was $86.72 \mathrm{~nm}$ and the polydispersity index (PdI) was low (less than 0.3 ), indicating a formulation with low polydisperse nanoparticles (Figure 1c). In addition, AgNPs showed a negative zeta potential $(-28.6 \mathrm{mV})$ (Figure 1d).

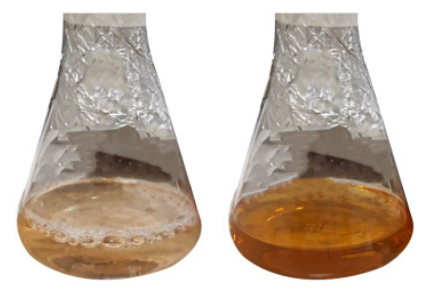

(a)

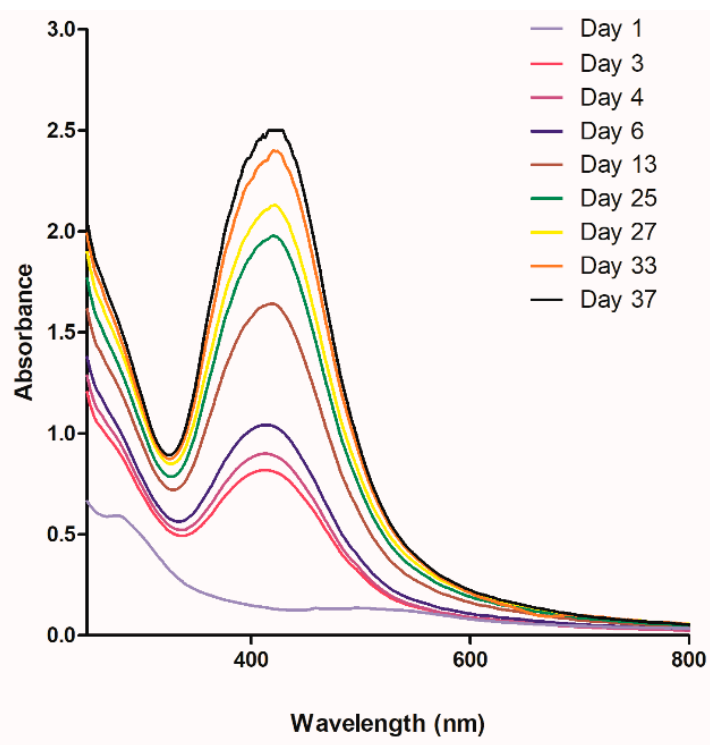

(b)

Figure 1. Cont. 


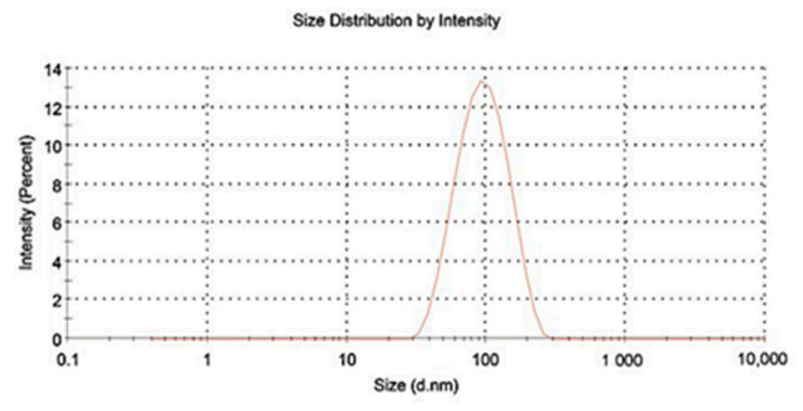

(c)

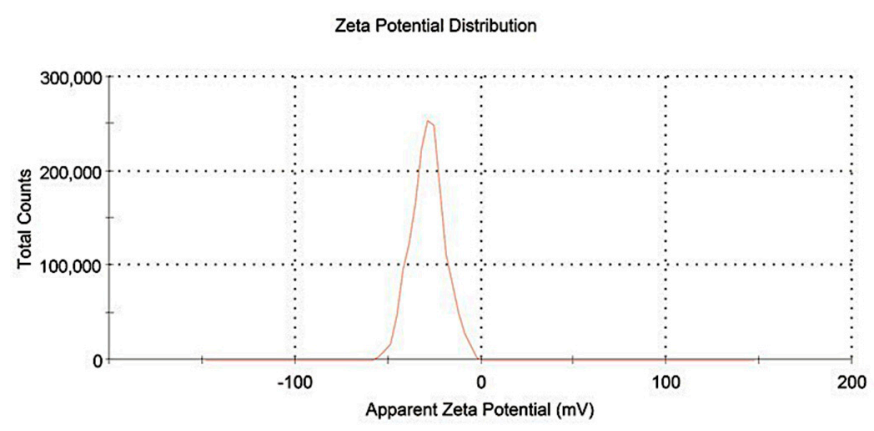

(d)

Figure 1. AgNPs biosynthesized by Fusarium oxysporum. (a) Fungal filtrate on the 1st day (left) and 15th day (right) after addition of silver nitrate $\left(\mathrm{AgNO}_{3}\right)$; (b) UV-Vis absorption spectrum of fungal filtrate after addition of $\mathrm{AgNO}_{3}$; (c) $\mathrm{AgNPs}$ size distribution by intensity (Z-average $86.72 \mathrm{~nm}$ ); and (d) Zeta potential distribution $(-28.6 \mathrm{mV})$.

The transmission electron microscopy (TEM) micrographs presented a heterogeneous size distribution, mostly spherical and measuring $16-33 \mathrm{~nm}$ (Figure $2 \mathrm{a}-\mathrm{c}$ ). The presence of an elemental silver signal in the colloidal dispersion was confirmed by Energy dispersive X-ray (EDX) spectrum (Figure 2d).
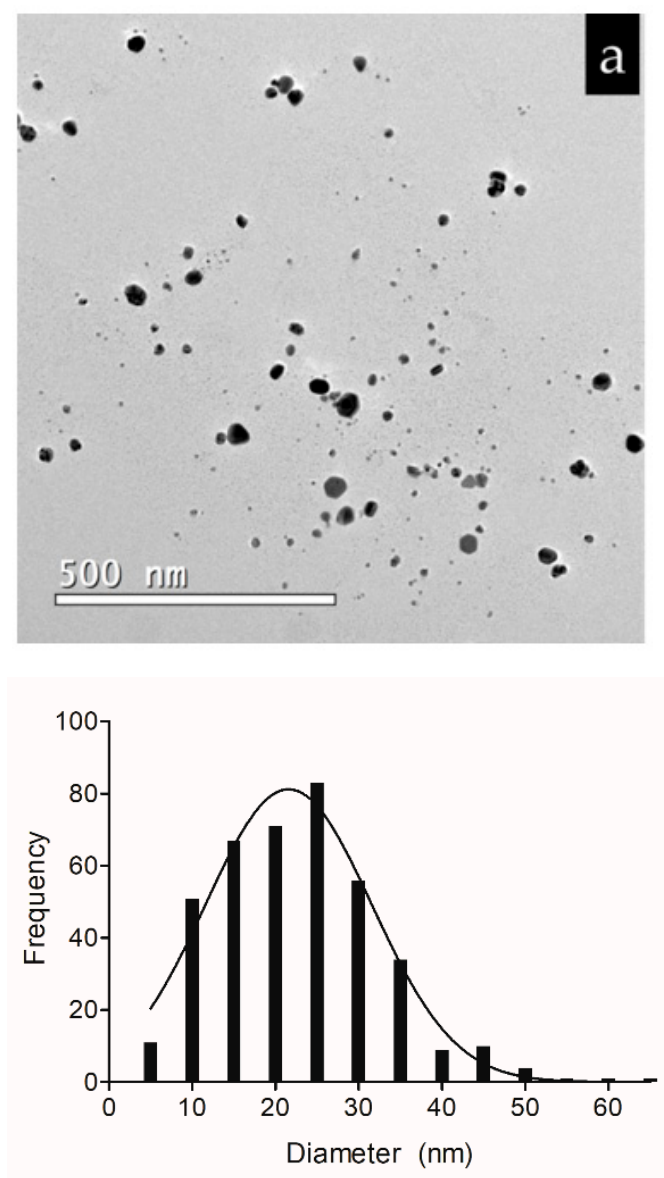

(c)
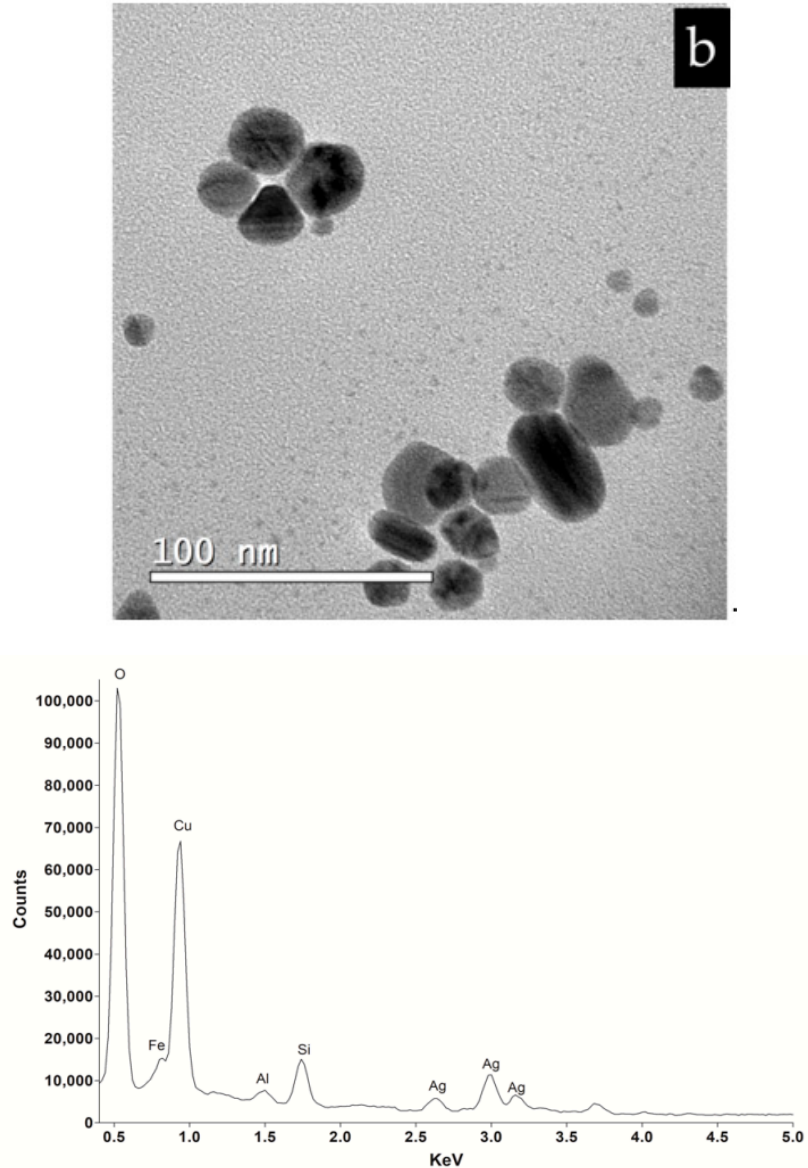

(d)

Figure 2. Micrographs of biosynthesized AgNPs obtained by TEM. (a) Distribution of AgNPs on a scale of $500 \mathrm{~nm}$; (b) AgNPs on a scale of $100 \mathrm{~nm}$ with morphology mostly spherical. (c) Histogram of the size distribution of AgNPs according to micrographs obtained by TEM ( $\mathrm{n}=403)$. (d) Energy dispersive X-ray (EDX) spectrum of AgNPs. 


\subsection{The Association of AgNPs with MB, NMBN, and NMBN-Zn}

The AgNPs-PS were characterized by variations in the formation of the surface plasmon band. The absorption graphs show curves of AgNPs, PS (MB, NMBN, and NMBN-Zn), and also of AgNPs-PS (Figure 3a-c).

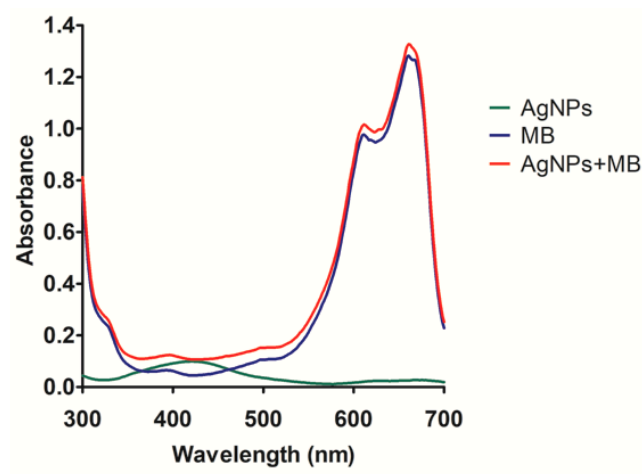

(a)

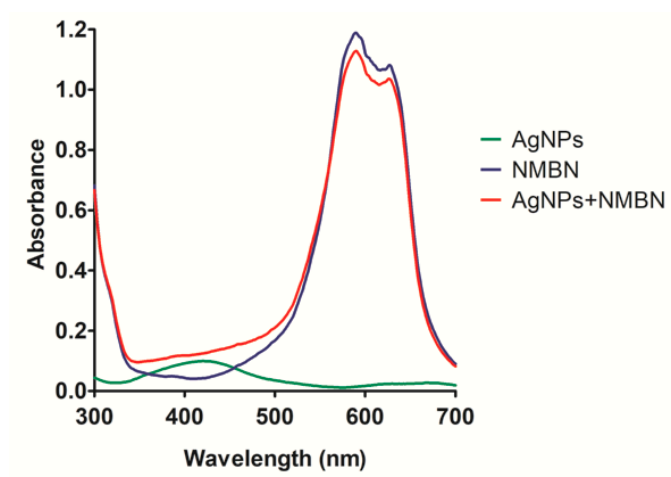

(b)

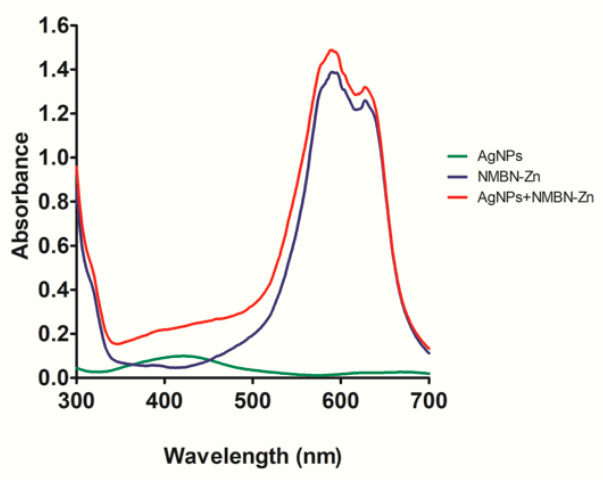

(c)

Figure 3. Optical absorption spectrum of AgNPs-PS associations compared to the isolated compounds. (a) AgNPs $\left(1.51 \mu \mathrm{g} \mathrm{mL}^{-1}\right), \mathrm{MB}\left(6.39 \mu \mathrm{g} \mathrm{mL}^{-1}\right)$, and AgNPs-MB $\left(1.51 \mu \mathrm{g} \mathrm{mL} \mathrm{mL}^{-1}\right.$ and $\left.6.39 \mu \mathrm{g} \mathrm{mL}^{-1}\right)$; (b) AgNPs $\left(1.32 \mu \mathrm{g} \mathrm{mL}^{-1}\right)$, NMBN $\left(6.95 \mu \mathrm{g} \mathrm{mL}^{-1}\right)$, and AgNPs-NMBN $\left(1.32 \mu \mathrm{g} \mathrm{mL}^{-1}\right.$ and $\left.6.95 \mu \mathrm{g} \mathrm{mL}^{-1}\right)$; and (c) AgNPs $\left(2.56 \mu \mathrm{g} \mathrm{mL}^{-1}\right), \mathrm{NMBN}-\mathrm{Zn}\left(8.33 \mu \mathrm{g} \mathrm{mL}^{-1}\right)$, and AgNPs-NMBN-Zn $\left(2.56 \mu \mathrm{g} \mathrm{mL}^{-1}\right.$ and $\left.8.33 \mu \mathrm{g} \mathrm{mL}^{-1}\right)$.

The compounds (green and blue curves) and AgNPs-PS association (red curves) showed the presence of AgNPs through the altered plasmon band around $420 \mathrm{~nm}$ and the respective PS in their maximum absorption peaks (MB, $655 \mathrm{~nm}$; NMBN $624 \mathrm{~nm}$; NMBN-Zn $627 \mathrm{~nm}$ ) (Figure 3a-c). The optical absorption spectrum graphs of AgNPs-PS presented an extension in the plasmon band, indicating that the presence of PS altered the electron distribution on the AgNPs surface. Zeta potential was measured to assess the influence of the presence of PS associated with AgNPs. As a result, it was observed that the zeta potential of AgNPs-MB, AgNPs-NMBN, and AgNPs-NMBN-Zn were $-13.9 \mathrm{mV},-17 \mathrm{mV}$, and $-9.25 \mathrm{mV}$, respectively, meaning that zeta potential decreased due to the presence of cationic phenothiazinium photosensitizers.

\subsection{Antifungal Activity of AgNPs-PS in APDT}

The antifungal activity of APDT with each PS (MB, NMBN, and NMBN-Zn), biosynthesized AgNPs, and AgNPs-PS (AgNPs-MB, AgNPs-NMBN, and AgNPs-NMBN-Zn) was evaluated in the dark and combined with different radiant exposures of red light $(5,10$, and $15 \mathrm{~J} \mathrm{~cm}^{-2}$ ). Exposure to red light (at all radiant exposures) in the absence of the PS and AgNPs did not inhibit the growth of $C$. albicans and F. keratoplasticum (data not shown). The minimum inhibitory concentration (MIC) value of AgNPs at $0,5,10$, and $15 \mathrm{~J} \mathrm{~cm}^{-2}$ were 
$1.56 \mu \mathrm{g} \mathrm{mL} \mathrm{m}^{-1}$ and $6.25 \mu \mathrm{g} \mathrm{mL} \mathrm{L}^{-1}$ against $C$. albicans and F. keratoplasticum, respectively. The AgNPs present an absorption peak around $420 \mathrm{~nm}$ and the antifungal effect is not influenced by red light (emission spectrum between 600 and $650 \mathrm{~nm}$ ), justifying the same MIC for dark and all radiant exposures. The treatment in the dark with the highest concentration of MB $\left(>12.79 \mu \mathrm{g} \mathrm{mL}^{-1}\right)$, NMBN $\left(>13.91 \mu \mathrm{g} \mathrm{mL}^{-1}\right)$, and NMBN-Zn $\left(>16.66 \mu \mathrm{g} \mathrm{mL}^{-1}\right)$ did not inhibit the growth of either fungus. The radiant exposure of $15 \mathrm{~J} \mathrm{~cm}^{-2}$ showed the best conditions for APDT with MB, NMBN, and NMBN-Zn antifungal activity. Additionally, it was noted that the greater the radiant exposure, the lesser the amount of PS needed to inhibit the growth of microorganisms (Tables 1 and 2).

Table 1. Minimum inhibitory concentration (MIC) of AgNPs $\left(\mu \mathrm{g} \mathrm{mL}{ }^{-1}\right)$, phenothiazinium PS (MB, NMBN, and NMBN-Zn in $\left.\mu \mathrm{g} \mathrm{mL}^{-1}\right)$, and AgNPs-PS in antimicrobial photodynamic treatment (APDT) against $C$. albicans.

\begin{tabular}{|c|c|c|c|c|}
\hline $\begin{array}{c}\text { Compound/ } \\
\text { Radiant Exposure }\end{array}$ & $0 \mathrm{~J} \mathrm{~cm}^{-2}$ & $5 \mathrm{~J} \mathrm{~cm}^{-2}$ & $10 \mathrm{~J} \mathrm{~cm}^{-2}$ & $15 \mathrm{~J} \mathrm{~cm}^{-2}$ \\
\hline $\mathrm{AgNO}_{3}$ & 1.56 & 1.56 & 1.56 & $0.39 *$ \\
\hline AgNPs & 1.56 & 1.56 & 1.56 & $1.56^{*}$ \\
\hline $\mathrm{MB}$ & $>12.79$ & 12.79 & 6.39 & $1.59 *$ \\
\hline NMBN & $>13.91$ & 1.73 & 0.86 & $0.43 *$ \\
\hline NMBN-Zn & $>16.66$ & 2.08 & 1.04 & $0.52 *$ \\
\hline AgNPs-MB & $1.56 / 12.79$ & $1.56 / 12.79$ & $0.78 / 6.39$ & $0.39 * / 1.59 *$ \\
\hline AgNPs-NMBN & $1.56 / 13.91$ & $1.56 / 13.91$ & $0.04 / 0.21$ & $0.04 * / 0.21 *$ \\
\hline AgNPs-NMBN-Zn & $1.56 / 16.66$ & $0.04 / 0.52$ & $0.04 / 0.52$ & $0.04 * / 0.13 *$ \\
\hline
\end{tabular}

$\mathrm{AgNO}_{3}$, silver nitrate; AgNPs, silver nanoparticles; MB, methylene blue; NMBN, new methylene blue N; NMBN$\mathrm{Zn}$, new methylene blue N Zinc; *, concentration $\left(\mu \mathrm{g} \mathrm{mL}^{-1}\right)$ used in antifungal survival test.

Table 2. Minimum inhibitory concentration (MIC) of AgNPs $\left(\mu g \mathrm{~mL}^{-1}\right)$, phenothiazinium PS (MB, NMBN, and NMBN-Zn in $\mu \mathrm{g} \mathrm{mL}^{-1}$ ), and AgNPs-PS in antimicrobial photodynamic treatment (APDT) against F. keratoplasticum.

\begin{tabular}{|c|c|c|c|c|}
\hline $\begin{array}{c}\text { Compound/ } \\
\text { Radiant Exposure }\end{array}$ & $0 \mathrm{~J} \mathrm{~cm}^{-2}$ & $5 \mathrm{~J} \mathrm{~cm}^{-2}$ & $10 \mathrm{~J} \mathrm{~cm}^{-2}$ & $15 \mathrm{~J} \mathrm{~cm}^{-2}$ \\
\hline $\mathrm{AgNO}_{3}$ & 1.56 & 3.12 & 3.12 & $0.78 *$ \\
\hline AgNPs & 6.25 & 6.25 & 6.25 & $6.25 *$ \\
\hline MB & $>12.79$ & 3.19 & 1.59 & $1.59 *$ \\
\hline NMBN & $>13.91$ & 0.86 & 0.86 & $0.21 *$ \\
\hline NMBN-Zn & $>16.66$ & 2.08 & 1.04 & $0.26 *$ \\
\hline AgNPs-MB & $1.56 / 12.79$ & $0.78 / 0.79$ & $0.78 / 0.79$ & $0.78 * / 0.79 *$ \\
\hline AgNPs-NMBN & $1.56 / 13.91$ & $0.39 / 0.43$ & $0.39 / 0.21$ & $0.39 * / 0.10 *$ \\
\hline AgNPs-NMBN-Zn & $1.56 / 16.66$ & $0.39 / 0.26$ & $0.39 / 0.26$ & $0.39 * / 0.26 *$ \\
\hline
\end{tabular}

$\mathrm{AgNO}_{3}$, silver nitrate; AgNPs, silver nanoparticles; MB, methylene blue; NMBN, new methylene blue N; NMBN$\mathrm{Zn}$, new methylene blue $\mathrm{N}$ Zinc; ${ }^{*}$, concentration $\left(\mu \mathrm{g} \mathrm{mL}^{-1}\right)$ used in antifungal survival test.

The association of PS with AgNPs was carried out with a concentration gradient based on the MIC of isolated PS and AgNPs against $C$. albicans and F. keratoplasticum. They were mixed in different concentrations particularly aiming to enhance the antifungal activity of APDT by using low amounts of the compounds (Tables 1 and 2). For C. albicans, a synergistic effect was observed in AgNPs-NMBN with a fractional inhibitory concentration index (FICI) of $0.26\left(10 \mathrm{~J} \mathrm{~cm}^{-2}\right)$ and $0.5\left(15 \mathrm{~J} \mathrm{~cm}^{-2}\right)$; and AgNPs-NMBN-Zn presented FICI of $0.5\left(10 \mathrm{~J} \mathrm{~cm}^{-2}\right)$ and $0.35\left(15 \mathrm{~J} \mathrm{~cm}^{-2}\right)$ (Table 3). For F. keratoplasticum, AgNPs-NMBN also presented a synergistic effect with FICI of $0.3\left(10 \mathrm{~J} \mathrm{~cm}^{-2}\right)$ and $0.5\left(15 \mathrm{~J} \mathrm{~cm}^{-2}\right)$; and AgNPs-NMBN-Zn presented FICI of $0.18\left(5 \mathrm{~J} \mathrm{~cm}^{-2}\right)$ and $0.31\left(10 \mathrm{~J} \mathrm{~cm}^{-2}\right)$ (Table 4) [13,14]. 
Table 3. Fractional inhibitory concentration index (FICI) of APDT with AgNPs-PS in C. albicans.

\begin{tabular}{|c|c|c|c|c|c|c|}
\hline \multirow{2}{*}{$\begin{array}{c}\text { Compound/ } \\
\text { Radiant Exposure }\end{array}$} & \multicolumn{2}{|c|}{$5 \mathrm{~J} \mathrm{~cm}^{-2}$} & \multicolumn{2}{|c|}{$10 \mathrm{~J} \mathrm{~cm}^{-2}$} & \multicolumn{2}{|c|}{$15 \mathrm{~J} \mathrm{~cm}^{-2}$} \\
\hline & FICI & Effect & FICI & Effect & FICI & Effect \\
\hline AgNPs-MB & 2.0 & indifferent & 1.5 & indifferent & 1.25 & indifferent \\
\hline AgNPs-NMBN & 9.0 & antagonistic & 0.26 & synergistic & 0.5 & synergistic \\
\hline AgNPs-NMBN-Zn & 0.3 & synergistic & 0.5 & synergistic & 0.3 & synergistic \\
\hline
\end{tabular}

AgNPs, silver nanoparticles; MB, methylene blue; NMBN, new methylene blue N; NMBN-Zn, new methylene blue N Zinc.

Table 4. Fractional inhibitory concentration index (FICI) of AgNPs-PS in F. keratoplasticum.

\begin{tabular}{|c|c|c|c|c|c|c|}
\hline \multirow{2}{*}{$\begin{array}{c}\text { Compound/ } \\
\text { Radiant Exposure }\end{array}$} & \multicolumn{2}{|c|}{$5 \mathrm{~J} \mathrm{~cm}^{-2}$} & \multicolumn{2}{|c|}{$10 \mathrm{~J} \mathrm{~cm}^{-2}$} & \multicolumn{2}{|c|}{$15 \mathrm{~J} \mathrm{~cm}^{-2}$} \\
\hline & FICI & Effect & FICI & Effect & FICI & Effect \\
\hline AgNPs-MB & 0.37 & synergistic & 0.6 & additive & 0.6 & additive \\
\hline AgNPs-NMBN & 0.56 & additive & 0.30 & synergistic & 0.5 & synergistic \\
\hline AgNPs-NMBN-Zn & 0.18 & synergistic & 0.31 & synergistic & 1.1 & indifferent \\
\hline
\end{tabular}

AgNPs, silver nanoparticles; MB, methylene blue; NMBN, new methylene blue N; NMBN-Zn, new methylene blue N Zinc.

Survival of C. albicans and F. keratoplasticum were tested in APDT in the dark (control) and red light $\left(15 \mathrm{~J} \mathrm{~cm}^{-2}\right)$. The concentrations of each compound were based on the respective MIC found in the susceptibility test with a radiant exposure of $15 \mathrm{~J} \mathrm{~cm}^{-2}$ (Tables 1 and 2). The red light did not affect $C$. albicans survival, and the number of surviving yeasts was close to the initial inoculum $\left(1 \times 10^{7} \mathrm{CFU} \mathrm{mL}{ }^{-1}\right)$. As expected, $\mathrm{AgNO}_{3}$ in both dark and red light killed most of the yeasts and only $1 \times 10^{2} \mathrm{CFU} \mathrm{mL} \mathrm{m}^{-1}$ survived (Figure 4a). AgNPs showed fungal survival of $1 \times 10^{5} \mathrm{CFU} \mathrm{mL}^{-1}$ in both dark and red light. As result, it was observed that in the dark, both isolated PS and those associated with AgNPs did not kill the yeasts. In the presence of red light, both PS and the associations showed a significant reduction in survival of $C$. albicans $(p<0.05)$ (Figure $4 a)$. Therefore, the concentrations of PS and AgNPs-PS that inhibited the growth (MIC) of the fungi in APDT were also able to kill C. albicans yeasts.

The red light did not affect $F$. keratoplasticum, and the number of surviving microconidia was close to the initial inoculum $\left(1 \times 10^{6} \mathrm{CFU} \mathrm{mL}{ }^{-1}\right)$. In the presence of $\mathrm{AgNO}_{3}$ and AgNPs in both dark and red light $\left(15 \mathrm{~J} \mathrm{~cm}^{-2}\right)$, there were no survivors (Figure $\left.4 \mathrm{~b}\right)$. As a result, it was observed that in the dark, both PS isolated and PS associated with AgNPs did not kill microconidia. In the presence of red light, both PS and AgNPs-PS showed a significant reduction in the survival of F. keratoplasticum microconidia $(p<0.05)$ (Figure $4 \mathrm{~b}$ ). Therefore, the concentrations of PS and associations that inhibited the growth (MIC) of the fungi in APDT were also able to kill F. keratoplasticum microconidia. 


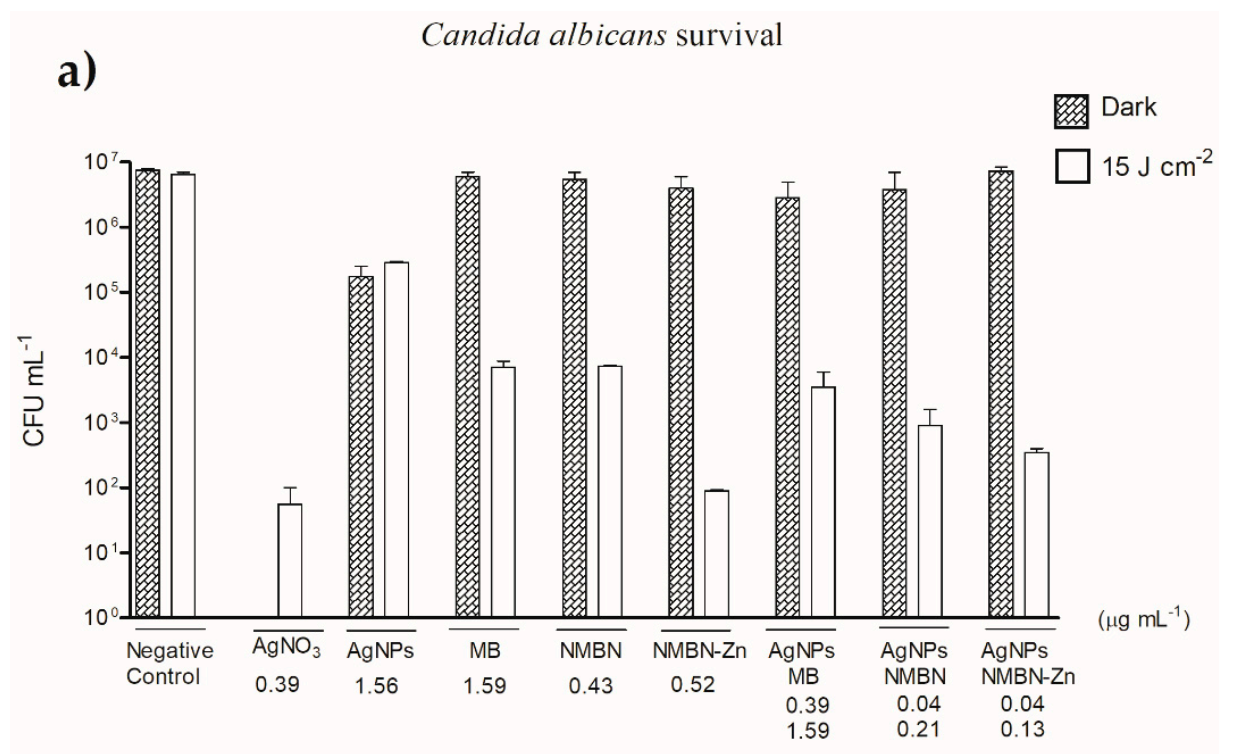

b)

Fusarium keratoplasticum survival

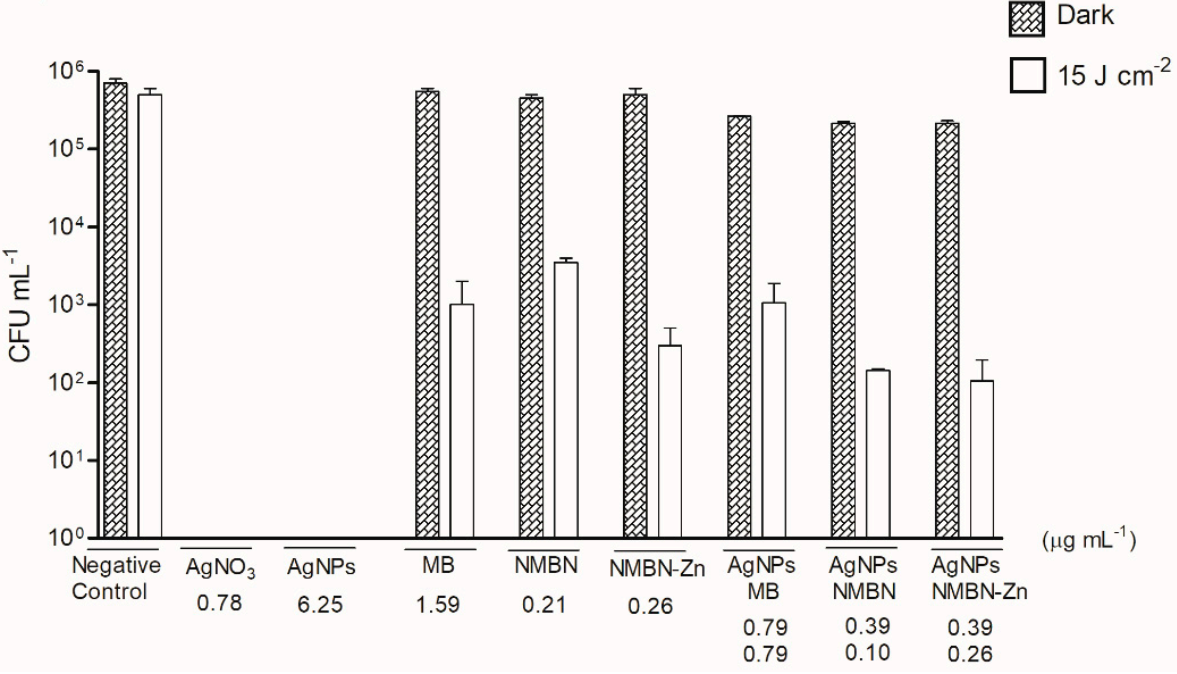

Figure 4. Antifungal survival test. The effect of APDT with the radiant exposure of $15 \mathrm{~J} \mathrm{~cm}^{-2}$ on the survival of the yeasts of C. albicans (a) and filamentous fungus F. keratoplasticum. (b) The concentrations of the compounds are shown in Tables 1 and 2. Error bars are the standard deviation of three independent experiments. CFU, colony-forming units; Negative control, dark and red light $\left(15 \mathrm{~J} \mathrm{~cm}^{-2}\right) ; \mathrm{AgNO}_{3}$, silver nitrate; AgNPs, silver nanoparticles; $\mathrm{MB}$, methylene blue; NMBN, new methylene blue N; NMBN-Zn, new methylene blue N Zinc.

The toxicity of APDT with $\mathrm{AgNO}_{3}, \mathrm{AgNPs}$, PS (MB, NMBN, and NMBN-Zn), and the AgNPs-PS (AgNPs-MB, AgNPs-NMBN, and AgNPs-NMBN-Zn) was evaluated with larvae of Galleria mellonella, an invertebrate and non-rodent model of virulence and toxicity. Table 5 shows the doses of each compound injected in G. mellonella. All control larvae of the experiment (naïve and phosphate buffered saline-PBS) exposed to dark and red light $\left(15 \mathrm{~J} \mathrm{~cm}^{-2}\right)$ survived until the end of the experiment (Figures $5 \mathrm{a}$ and 6$)$. The positive control $\left(\mathrm{AgNO}_{3}\right)$ showed a gradual increase in death of larvae with the increase in the compound concentration, in exposure to both dark and red light (Figure 5b,c, Supplementary Figure S1). The highest concentration of $\mathrm{AgNO}_{3}$ reduced the larvae population to $40 \%$ in 5 days (Figure 6). The dark and red light $\left(15 \mathrm{~J} \mathrm{~cm}^{-2}\right)$ treatments with AgNPs, MB, NMBN, NMBN-Zn, and associations (AgNPs-MB, AgNPs-NMBN, and AgNPs-NMBN-Zn) did not present toxicity to G. mellonella larvae at the maximum tested doses for AgNPs $\left(5 \mathrm{mg} \mathrm{kg}^{-1}\right)$, 
MB (20.83 mg kg $\left.{ }^{-1}\right)$, NMBN (26.31 $\left.\mathrm{mg} \mathrm{kg}^{-1}\right)$, and NMBN-Zn $\left(16 \mathrm{mg} \mathrm{kg}^{-1}\right.$ ) (Figure 6, supplementary Figure S1).

Table 5. Doses of compounds injected in Galleria mellonella.

\begin{tabular}{cccccc}
\hline \multirow{2}{*}{$\begin{array}{c}\text { Compound } \\
\left(\mathbf{m g ~ k g}^{-\mathbf{1}}\right)\end{array}$} & $\mathbf{1}$ & $\mathbf{2}$ & $\mathbf{3}$ & $\mathbf{4}$ & $\mathbf{5}$ \\
\cline { 2 - 6 } & 0.31 & 0.62 & 1.25 & 2.5 & 5.0 \\
$\mathrm{AgNO}_{3}$ & 0.31 & 0.62 & 1.25 & 2.5 & 5.0 \\
$\mathrm{AgNPs}$ & 1.3 & 2.6 & 5.2 & 10.41 & 20.83 \\
$\mathrm{MB}$ & 1.64 & 3.28 & 6.57 & 13.15 & 26.31 \\
$\mathrm{NMBN}$ & 1.04 & 2.08 & 4.16 & 8.3 & 16.6 \\
$\mathrm{NMBN}-\mathrm{Zn}$ & $0.31 / 1.13$ & $0.62 / 2.6$ & $1.25 / 5.20$ & $2.5 / 10.4$ & $5.0 / 20.83$ \\
AgNPs-MB & $0.31 / 1.64$ & $0.62 / 3.28$ & $1.25 / 6.57$ & $2.5 / 13.15$ & $5.0 / 26.31$ \\
AgNPs-NMBN & $0.31 / 1.04$ & $0.62 / 2.08$ & $1.25 / 4.16$ & $2.5 / 8.3$ & $5.0 / 16.6$ \\
AgNPs-NMBN-Zn & &
\end{tabular}

$\mathrm{AgNO}_{3}$, silver nitrate; AgNPs, silver nanoparticles; MB, methylene blue; NMBN, new methylene blue N; NMBN$\mathrm{Zn}$, new methylene blue N Zinc.

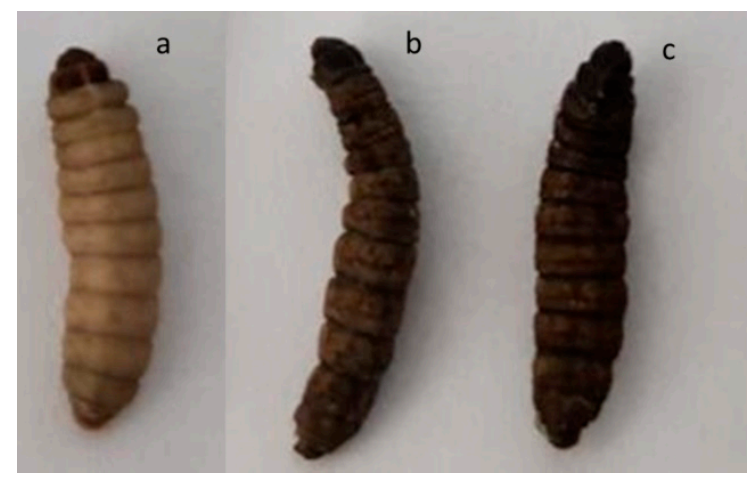

Figure 5. Galleria mellonella larvae. (a) Healthy larva without treatment (naïve); (b) dead larvae after $\mathrm{AgNO}_{3}$ in exposure to dark; (c) dead larvae after $\mathrm{AgNO}_{3}$ in exposure to red light $\left(15 \mathrm{~J} \mathrm{~cm}^{-2}\right)$.

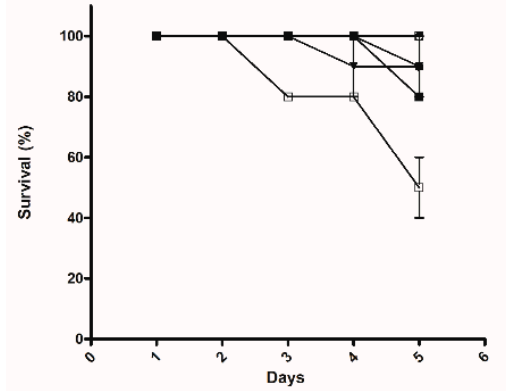

(a)

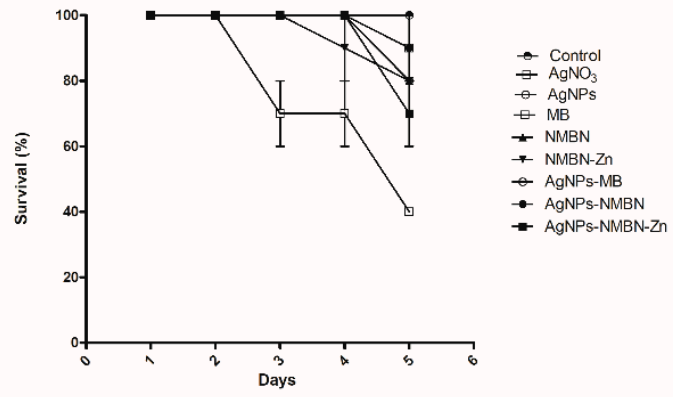

(b)

Figure 6. Toxicity of APDT in G. mellonella larvae. Larvae were inoculated with the compounds $\mathrm{AgNO}_{3}, \mathrm{AgNPs}_{\mathrm{S}} \mathrm{MB}, \mathrm{NMBN}$, NMBN-Zn, and associations. The concentration of each compound injected in G. mellonella larvae is shown in Table 5, group of the larvae number 5. (a) Survival of G. mellonella larvae over the days in the dark; (b) survival of G. mellonella larvae over the days after APDT $15 \mathrm{~J} \mathrm{~cm}^{-2}$. Control, naïve and PBS; $\mathrm{AgNO}_{3}$, silver nitrate; AgNPs, silver nanoparticles; $\mathrm{MB}$, methylene blue; NMBN, new methylene blue N; NMBN-Zn, new methylene blue N Zinc; associations AgNPs-MB, AgNPs-NMBN, and AgNPs-NMBN-Zn.

\section{Discussion}

The frequency of mycoses due to opportunistic and multi-resistant fungal pathogens has increased significantly over the past decades $[1,3]$. The field of medical mycology therapy has become an extremely challenging study, making the search for new alternatives for the treatment of fungal infections important. APDT and AgNPs are promising alternative 
therapies due to their well-known antimicrobial activity. In this context, we studied the antifungal activity effect of APDT against the yeast fungus $C$. albicans and the filamentous fungus F. kertoplasticum to find synergistic effect using low concentrations of phenothiazinium photosensitizers (PS) methylene blue (MB), new methylene blue N (NMBN), and new methylene blue N Zinc (NMBN-Zn) in association with biosynthesized AgNPs.

Each PS (MB, NMBN, and NMBN-Zn) has high selectivity for F. keratoplasticum and C. albicans [6,15]. Additionally, the relationship of metal ions such as $\mathrm{Zn}^{2+}$ and $\mathrm{Al}^{3+}$ positively influences the photodynamic effect, increasing the production of PS molecules in triplet state and production of singlet oxygen $[16,17]$. Recently, metallic nanoparticles associated with photosensitizers were explored. Gold nanoparticles associated with toluidine blue (TBO) increased the bactericidal effect of APDT against Staphylococcus aureus by 90 to $99 \%[18,19]$. AgNPs associated with TBO against Streptococcus mutans also increased bactericidal effect $[9,20]$. The use of F. oxysporum for AgNPs biosynthesis is well described [21-24]. The biomolecules secreted by the microbial biomass can act as reducing and capping agents during the synthesis of metallic nanoparticles [25]. The relation between biomass composition and metal nanoparticle formation is not clearly elucidated and described in the literature. However, it has been previously verified that different fungi produce reducing agents (e.g., naphthoquinone anthraquinones) and reductase enzymes capable of transferring electrons to silver ions $\left(\mathrm{Ag}^{+}\right)$[22,24]. Although biomass analysis was not performed in this work, the presence of several intra and extracellular proteins and compounds from F. oxysporum (e.g., beta-glucosidase, beta-amylase, peroxiredoxin [26], glycoproteins (60-70 kDa) [27], cationic proteins (24 and $28 \mathrm{KDa})$ [28], reductases [26], calnexin [29], anthraquinones [30]) has been described. The presence of proteins, hydrolytic enzymes, and reductases depends on which source of nitrogen is used. Therefore, nutrients are important factors that must be studied to improve the quality and efficiency of AgNPs production in the future [31].

The first characteristic observed in AgNPs biosynthesis was the change in dispersion color from yellow to brown and the presence of a band at $420 \mathrm{~nm}$ that occurs due to surface plasmon resonance, which is the differentiated movement of electrons in the metal's electronic bands that are on the surface of nanoparticles [32,33]. The wavelength of the plasmon band is closely related to the size, shape, and distribution of compounds bound to the surface of the AgNPs. Thus, the wider the peak of the plasmon band, the higher the PdI; and the greater the wavelength, the larger the size of AgNPs. Mie's theory [34] suggests spherical-shaped nanoparticles have a single peak in the absorption spectrum, while particles of other shapes such as triangular or flat disc-shaped may have two or more bands due to their shape and diameter. Based on this theory, the biosynthesis of nanoparticles by F. oxysporum showed a single narrow peak located at the $420 \mathrm{~nm}$ wavelength, which means spherical AgNPs with an approximate size of $30 \mathrm{~nm}$. Additionally, these data corroborate with results of dynamic light scattering (DLS) and the PdI. Through TEM analysis, it was possible to obtain the average diameter of AgNPs, of which $80 \%$ are between 16 and $33 \mathrm{~nm}$. The difference in the size of AgNPs between the DLS and TEM technique is justified by the DLS technique to measure the size of AgNPs in aqueous dispersion, which may be larger due to other compounds from biological synthesis (proteins, for example) that can be bound to nanoparticles [35,36]. Marcato et al. $(2015,2012)$ and Birla et al. $(2013)$ verified, by Fourier Transform Infrared Spectroscopy (FTIR), the presence of protein capping around AgNPs biosynthesized by F. oxysporum [37-39]. AgNPs showed a negative zeta potential $(-28.6 \mathrm{mV})$ due to the fungus protein capping around silver nanoparticles, as also described previously [38,39]. Furthermore, through X-ray Powder Diffraction (XRD), Gaikwad et al. (2013) confirmed that biogenic AgNPs prepared using F. oxysporum are crystalline [40].

The wide plasmon band observed in Figure $1 \mathrm{~b}$ indicates the heterogeneity of the particles that is characteristic of the biological synthesis method [21,22]. This heterogeneity was confirmed by the PdI values in the DLS analysis. In comparison with biosynthesis, chemical synthesis of AgNPs generally results in samples with low PdI values due to the possibility of having greater control over reaction variables, such as reducing agent, 
salt silver, temperature, $\mathrm{pH}$, and stabilizing agents [41]. However, biosynthesis is more advantageous as it is a simpler and cheaper method that does not use toxic agents and does not require sample purification steps to remove the excess of reagents or residual compounds $[42,43]$. AgNPs biosynthesized by F. oxysporum presented a moderate PdI, possibly due to the presence of different reducing agents excreted in the medium by the microorganism that make synthesis differentiated. Furthermore, microorganisms excrete enzymes that catalyze the reaction and proteins that will stabilize nanoparticles without the need to add stabilizing agents, such as polymers [44,45].

The biosynthesized AgNPs associated to MB, NMBN, and NMBN-Zn showed an absorption spectrum peak around $420 \mathrm{~nm}$, which represents the presence of AgNPs, and an additional peak between $600-650 \mathrm{~nm}$, which shows the presence of PS [18,19]. For AgNPs-PS, a decrease in the intensity and an enlargement of the plasmon band at $420 \mathrm{~nm}$ were observed. This is justified by the binding of PS to the surface of AgNPs that changes the movement of electrons and increases the diameter of the nanoparticle. Additionally, a change in zeta potential value was observed in AgNPs-PS, as expected [46].

The antifungal activity of AgNPs disrupts the cell wall and plasma membrane and increases the production of ROS that leads to cell death [47-49]. AgNPs showed antifungal activity against C. albicans and F. keratoplasticum, and the MICs were $1.56 \mu \mathrm{g} \mathrm{mL}^{-1}$ and 6.25 $\mu \mathrm{g} \mathrm{mL}{ }^{-1}$, respectively. The MICs of AgNPs in the presence of red light were identical to those found in the absence of light (darkness). This is justified by the fact that the spectrum of red light used in the experiment is in the $600 \mathrm{~nm}$ range, with the maximum emission peak at $635 \mathrm{~nm}$ [6] while the spectrum absorption rates of AgNPs are around $420 \mathrm{~nm}$. The photosensitizers MB and NMBN-Zn have antifungal activity in vitro and in vivo against Fusarium spp. [6,50], and in vitro activity against Candida spp. [15]. In this work, antifungal activity was evaluated by determining the MIC to evaluate the enhancement of the antifungal activity of AgNPs-PS associations in APDT compared to the isolated compounds. APDT with PS were tested and the most effective PS in APDT $\left(15 \mathrm{~J} \mathrm{~cm}^{-2}\right)$ against $C$. albicans and F. keratoplasticum was NMBN-Zn, followed by NMBN and MB. NMBN-Zn had the smallest MIC and its antifungal effect was described for Candida spp., Trichophyton spp., Fusarium spp., and Colletotrichum spp. [15,50-52].

The AgNPs-PS were tested for APDT antifungal activity and it was observed that among the three associations, AgNPs-NMBN-Zn was the most efficient against C. albicans with a synergistic effect presenting FICI of 0.3. For F. keratoplasticum, the most efficient association was AgNP-NMBN with a synergistic effect presenting FICI of 0.5. The efficiency of antifungal activity of APDT associations was also assessed by the survivor fraction method, in which AgNPs-MB, AgNPs-NMBN, and AgNPs-NMBN-Zn presented greater inhibition of $C$. albicans and F. keratoplasticum, reducing by approximately four orders of magnitude. The association of phenothiazinium PS with nanoparticles has been studied to increase the photodynamic effect, using them as a vehicle, or to increase the number of PS molecules in the triplet state, transferring energy to them. The use of phthalocyanine associated with gold nanoparticles was described and demonstrated an increase in singlet oxygen compared to free phthalocyanine [53]. A hybrid system of AgNPs, amphiphilic polymer, and hematoporphyrin verified a high efficiency in photodynamic inactivation of Staphylococcus epidermidis and Escherichia coli, as well as presenting low toxicity in cell cultures [54]. In a study, gold nanoparticles complexed to MB demonstrated that metallic nanoparticles act as a "quencher" for MB fluorescence, and photodynamic reaction also occurs with greater intensity through the type I photoprocess, producing hydroxyl radicals [55]. Thus, the association of PS with AgNPs in APDT is promising for the study and use in photodynamic therapy, aiming to increase its effect mainly in the treatment of fungal infections.

APDT with AgNPs-PS associations were tested for toxicity in vivo in the invertebrate model Galleria mellonella. The results obtained in experiments with the larvae reproduce several results obtained with mammals due to the similarity of their cells with the innate immune cells of mammals. The use of this model serves as a screening method for tests 
to decrease the use of mice and rats [56,57]. Its use has been described to assess virulence in microorganisms such as Cryptococcus neoformans [58], Candida albicans [59], and Fusarium spp. [50]. The biosynthesized AgNPs, the PS (MB, NMBN, and NMBN-Zn), and associations (AgNPs-MB, AgNPs-NMBN, and AgNPs-NMBN-Zn) were not able to kill the larvae at the maximum tested dose in APDT. Thus, APDT using PS associated with AgNPs has great potential for the treatment and control of opportunistic mycoses due to its enhanced antifungal activity against C. albicans and F. keratoplasticum and low toxicity in an invertebrate model of toxicity.

\section{Materials and Methods}

\subsection{Materials and Fungal Strains}

Fusarium oxysporum INCQS 40144 (ATCC ${ }^{\circledR} 48112^{\mathrm{TM}}$ ) obtained from the American Type Culture Collection (ATCC) (Manassas, VA, USA) was used to perform biosynthesis of AgNPs. The fungus was grown on Sabouraud dextrose agar (SDA, Neogen, MI, USA) at $28{ }^{\circ} \mathrm{C}$ for 5 days. The APDT experiments were performed with Fusarium keratoplasticum INCQS 40099 (ATCC 36031) and Candida albicans (ATCC 64548). F. keratoplasticum was grown in potato dextrose agar (Neogen, Lansing, MI, USA) at $28{ }^{\circ} \mathrm{C}$ for 5 days. The microconidia were subsequently harvested and resuspended in PBS. Candida albicans was grown on Sabouraud dextrose agar (SDA-Neogen, Lansing, MI, USA) at $35^{\circ} \mathrm{C}$ for $24 \mathrm{~h}$. Subsequently, 3 colonies were inoculated in Sabouraud Dextrose liquid culture medium (Neogen, Lansing, MI, USA) and incubated at $35^{\circ} \mathrm{C}$ and $180 \mathrm{rpm}$ (Infors HT Ecotron, Switzerland) for $24 \mathrm{~h}$. The liquid culture medium containing the C. albicans was centrifuged and the yeasts were resuspended in PBS. The concentration of microconidia and yeast suspension was determined by hemacytometer counts, and diluted with autoclaved PBS to the desired concentrations.

\subsection{Biosynthesis and Characterization of AgNPs}

Fusarium oxysporum biomass was gently harvested from SDA and each $10 \mathrm{~g}$ was added to $100 \mathrm{~mL}$ of sterile water at $25^{\circ} \mathrm{C}, 150 \mathrm{rpm}$ for 3 days. The biomass was subsequently removed by filtration and the filtrate was centrifuged at $4,000 \times g$ to remove the undesirable contaminants. Into $10 \mathrm{~mL}$ of supernatant were added $2 \mathrm{mg}$ of silver nitrate $\left(\mathrm{AgNO}_{3}\right.$ Sigma-Aldrich, Inc., St. Louis, MO, USA). The solution was stored in an amber flask at $26^{\circ} \mathrm{C} \pm 2{ }^{\circ} \mathrm{C}$ in the dark and the formation of AgNPs was observed by color change.

Absorbance spectra of AgNPs were taken for 37 days with a NanoPhotometer PClass spectrophotometer (IMPLEN GmbH, Munich, Germany) over the wavelength range 300-800 nm. DLS and Zeta Potential measurements were determined using Malvern Zetasizer Nano-ZS equipment (Malvern, UK). Furthermore, to analyze size and shape, AgNPs were subjected to TEM. The sample was dripped onto a $3 \mathrm{~mm}$ diameter copper grid coated with carbon, and TEM micrographs were captured in a JEOL/JEM 2100 LaB6 $200 \mathrm{kV}$ instrument (JEOL, Boston, MA, USA). Image J software (ImageJ 1.43a, version 64bits-National Institutes of Health, Bethesda, MD, USA) was used to measure the AgNPs diameter, and data analyses were performed using GraphPad Prism 5 software.

\subsection{Antimicrobial Photodynamic Therapy (APDT) with Phenothiazinium Photosensitizers and Association with AgNPs}

\subsubsection{Photosensitizers}

The photosensitizers (PS) used were the commercial phenothiaziniums methylene blue (methylene blue, $\mathrm{MB})\left(\mathrm{C}_{16} \mathrm{H}_{18} \mathrm{ClN}_{3} \mathrm{~S}\right)$, new methylene blue $\mathrm{N}$ (new methylene blue $\mathrm{N}$, $\mathrm{NMBN})\left(\mathrm{C}_{18} \mathrm{H}_{22} \mathrm{ClN}_{3} \mathrm{~S}\right)$, and new methylene blue $\mathrm{N}$ formula with zinc (new methylene blue $\mathrm{N}$ zinc chloride double salt, $\mathrm{NMBN}-\mathrm{Zn})\left(\mathrm{C}_{18} \mathrm{H}_{22} \mathrm{ClN}_{3} \mathrm{~S} \cdot 0.5 \mathrm{ZnCl}_{2}\right)$. All dyes were obtained from Sigma-Aldrich, Inc., MO, USA. 


\subsubsection{Light}

The APDT was evaluated with an arrangement of 96 LEDs (red light) with an emission spectrum between 600 and $650 \mathrm{~nm}$ (peak at $635 \mathrm{~nm}$ ). The irradiance measurement was $0.01523 \mathrm{~W} \mathrm{~cm}^{-2}$ and APDT experiments were carried out on radiant exposures of 5, 10, and $15 \mathrm{~J} \mathrm{~cm}^{-2}$, corresponding to the exposure times of $5.47 \mathrm{~min}, 10.94 \mathrm{~min}$, and $16.41 \mathrm{~min}$, respectively.

\subsubsection{The Association of AgNPs with MB, NMBN, and NMBN-Zn}

The PS and AgNPs solutions were prepared in autoclaved distilled water at concentrations of $82 \mu \mathrm{g} \mathrm{mL}^{-1}$ for $\mathrm{MB}, 70 \mu \mathrm{g} \mathrm{mL}{ }^{-1}$ for NMBN, $90 \mu \mathrm{g} \mathrm{mL}{ }^{-1}$ for NMBN-Zn, and $100 \mu \mathrm{g} \mathrm{mL}^{-1}$ for AgNPs. The concentrations for the AgNPs-PS were based on the compound concentrations used in MICs obtained from each compound for C. albicans and F. keratoplasticum. Thus, the lowest concentrations of PS and AgNPs capable of inhibiting the growth of fungi were mixed to form the AgNPs-PS.

The formation of the surface plasmon band of the AgNPs-PS was determined using the NanoPhotometer P-Class spectrophotometer (IMPLEN GmbH, Munich, Germany). The suspensions of AgNPs-PS were diluted in a proportion of 1:1 in distilled water, added into a quartz cuvette, with an optical path of $1 \mathrm{~cm}$, and scanning analysis from 300 to $800 \mathrm{~nm}$ was performed on a NanoPhotometer P-Class (IMPLEN GmbH, Munich, Germany). The behavior of the plasmon band of AgNPs was evaluated after the association with the PS in solution. It was also verified if there were changes in the absorption spectrum of the PS. The equipment reading was blanked with autoclaved distilled water that corresponds to the solvent of the synthesized AgNPs.

The hydrodynamic mean diameter (z-average), zeta potential, and polydispersity index of AgNPs-MB, AgNPs-NMBN, and AgNPs-NMBN-Zn were obtained using the DLS technique on the NanoSize ZS device (Malvern). The solutions were diluted $20 \times$ with distilled water in a polystyrene bucket for analysis of the hydrodynamic diameter. To measure the zeta potential, the dilution ratio was the same, but the sample was diluted in $1 \mathrm{mM} \mathrm{KCl}$ and added to the zeta potential cuvette (DTS 1070, Malvern).

The synergism between compounds was determined using the Fractional Inhibitory Concentration Index (FICI), in which synergy is less than or equal to 0.5. For values between 0.5 and 1.0, the compounds have additive effects; for values between 1.0 and 4.0, the effect is considered indifferent, and antagonism can be observed when the FICI values are above 4 [13].

4.3.4. Evaluation of APDT Effect on C. albicans and F. keratoplasticum Based on Minimum Inhibitory Concentration (MIC)

The antifungal activity of APDT with PS (MB, NMBN, and NMBN-Zn), AgNPs, and AgNPs-PS against C. albicans and F. keratoplasticum was determined by the MIC. The experiment was carried out following the guidelines of the microdilution method in broth protocols M38A2 and M27A3 of the Clinical and Laboratory Standards Institute (CLSI, 2008), with modifications. In a 96-well microplate (TPP, Trasadingen, Switzerland), $50 \mu \mathrm{L}$ of microconidia or yeast suspension and $50 \mu \mathrm{L}$ of the PS or AgNPs or AgNPs-PS were pipetted. The final concentration of microconidia was $1 \times 10^{5}$ cells mL $\mathrm{mL}^{-1}$ and $5 \times 10^{3}$ cells $\mathrm{mL}^{-1}$ of yeast. The MB concentration gradient was 0.02 to $12.79 \mu \mathrm{g} \mathrm{mL}^{-1}$, NMBN from 0.05 to $13.91 \mu \mathrm{g} \mathrm{mL}^{-1}$, and NMBN-Zn from 0.06 to $13.91 \mu \mathrm{g} \mathrm{mL}^{-1}$ for F. keratoplasticum and C. albicans. The gradients of AgNPs were 0.01 to $4 \mu \mathrm{gL}^{-1}$ for C. albicans, and 0.02 to $6.5 \mu \mathrm{g} \mathrm{mL}^{-1}$ for F. keratoplasticum. The microplates were kept in the dark for $30 \mathrm{~min}$ (pre-incubation) and were then exposed to red light at 5, 10, and $15 \mathrm{~J} \mathrm{~cm}^{-2}$. Subsequently, $100 \mu \mathrm{L}$ of RPMI 1640 culture medium (Sigma Aldrich, USA) twice concentrated buffered with 0.165 M MOPS (Sigma Aldrich, USA) were pipetted into each well of the 96-well plate. The plates were incubated at $28{ }^{\circ} \mathrm{C}$ for F. keratoplasticum and $35^{\circ} \mathrm{C}$ for C. albicans in the dark and the growth of the fungus was evaluated after $24 \mathrm{~h}$ of incubation. As a negative control, wells were made with PBS and RPMI 1640 culture medium (Sigma Aldrich, USA), 
and wells with RPMI 1640 culture medium (Sigma Aldrich, USA) plus PS, AgNPs, and AgNPs-PS. As a positive control, wells were made with RPMI 1640 (Sigma Aldrich, USA) plus cells (yeasts or microconidia). In parallel, a replica plate of the experiment was made without exposure to red light. The experiments were carried out in two biological replicates and in triplicate.

\subsubsection{Evaluation of APDT Effect Based on the Survival of C. albicans and F. keratoplasticum}

The survival of C. albicans and F. keratoplasticum was evaluated after APDT with the following compounds: $\mathrm{AgNO}_{3}$, AgNPs, MB, NMBN, NMBN-Zn, AgNPs-MB, AgNPs-NMBN, and AgNPs-NMBN-Zn. To assess cell survival (yeasts or microconidia) to APDT, $300 \mu \mathrm{L}$ of the compounds were mixed with $300 \mu \mathrm{L}$ of the cell suspension in $1.5 \mathrm{~mL}$ microtubes (polypropylene; Axygen Scientific, CA, USA). For C. albicans, the final concentration of yeast suspension was $1 \times 10^{7}$ cells $\mathrm{mL}^{-1}$ [15] and the compounds are described in Tables 1 and 2 . For F. keratoplasticum, the final microconidium concentration was $2 \times 10^{6}$ cells $\mathrm{mL}^{-1}$ [6]. The microtubes were kept in the dark for $30 \mathrm{~min}$ at $28{ }^{\circ} \mathrm{C}$ (pre-incubation). Subsequently, $600 \mu \mathrm{L}$ of each mixture were transferred to a 24-well plate well (TPP, Switzerland) and exposed to radiant exposures of 0 (control in the dark) and $15 \mathrm{~J} \mathrm{~cm}^{-2}$. The mixtures were then diluted with PBS, pH 7.0 in concentrations $10^{-1}$ to $10^{-3}$. The $50 \mu \mathrm{L}$ volume of each dilution was spread over the surface of $5 \mathrm{~mL}$ of potato dextrose agar, supplemented with $1 \mathrm{~g} \mathrm{~L}^{-1}$ of deoxycholic acid (sodium salt) (Fluka, Milano, Italy), in Petri dishes (60 $\mathrm{mm} \times 15 \mathrm{~mm}$ ). The plates were incubated in the dark at $37^{\circ} \mathrm{C}$, and colony counting started after $24 \mathrm{~h}$. The controls of the experiment were: cells exposed only to red light without the presence of treatments, and cells with all treatments without exposure to light (dark). Two biological replicates were performed, and for each treatment (mixture) three replication plates were made.

\subsection{Toxicity test in Galleria mellonella}

The toxicity of compounds $\mathrm{AgNO}_{3}, \mathrm{AgNPs}, \mathrm{MB}, \mathrm{NMBN}, \mathrm{NMBN}-\mathrm{Zn}$, and AgNPs-MB, AgNPs-NMBN, and AgNPs-NMBN-Zn were evaluated using larvae from the experimental toxicity model G. mellonella [60]. For each treatment, 5 larvae of G. mellonella (200 to $250 \mathrm{mg}$ ) were separated in the sixth instar of development in Petri dishes $(90 \mathrm{~mm} \times 15 \mathrm{~mm})$. Doses are described in Table 5. A Hamilton model 7000.5 KH micro-syringe was used to inject $5 \mu \mathrm{L}$ of inoculum containing the compounds into the hemocoel of each larva through the last right proleg. After inoculation, the larvae were kept in the dark for $30 \mathrm{~min}$ at $28^{\circ} \mathrm{C}$ and then exposed to radiant exposures of 0 (dark control) and $15 \mathrm{~J} \mathrm{~cm}^{-2}$. The experiment controls were larvae inoculated with PBS exposed and not exposed to light, and larvae that were not inoculated exposed and not exposed to light (naïve). After APDT, the larvae were incubated at $37^{\circ} \mathrm{C}$ and deprived of food and direct lighting. Larvae survival assessments were carried out every $24 \mathrm{~h}$ for 5 days and pre-pupae were also removed daily to delay metamorphosis. The experiment was conducted with two biological replicates.

\subsection{Statistics}

ANOVA and frequency distribution were performed using GraphPad Prism 5 statistical software. $p$-value $<0.05$ was considered statistically significant.

\section{Conclusions}

The enhancement of the antifungal activity of APDT with AgNPs-PS associations by using low concentrations of phenothiazinium photosensitizers (PS) methylene blue (MB), new methylene blue N (NMBN), and new methylene blue N Zinc (NMBN-Zn) in association with biosynthesized AgNPs against C. albicans and F. keratoplasticum is shown. The APDT with AgNPs, PS, and AgNPs-PS did not show toxicity at the concentrations tested in the in vivo toxicity model Galleria mellonella. Thus, the synergistic effect of AgNPs-PS in APDT and the non-toxicity in an in vivo model indicates this as a promising approach for 
the treatment of superficial mycoses, such as onychomycoses and dermatomycoses; however, more in vivo studies are needed to ensure safety in their use in humans and animals.

\section{Patents}

BR 1020200251708 filled in Brazil, on 19 December 2020. Title: "Composições compreendendo fotossensibilizadores fenotiazínicos associados à nanopartículas de prata utilizadas na terapia fotodinâmica antimicrobiana e uso destas na preparação de um medicamento para tratar infecções causadas por fungos".

Supplementary Materials: The following are available online at https://www.mdpi.com/article/10 .3390/antibiotics10050569/s1, Figure S1: Toxicity of APDT in G. mellonella larvae.

Author Contributions: Methodology, G.R.C., P.D.M., L.T., M.R.v.Z.K.; writing—original draft preparation, G.R.C.; writing—review and editing, M.R.v.Z.K.; visualization, P.D.M.; supervision, M.R.v.Z.K.; project administration, M.R.v.Z.K.; funding acquisition, M.R.v.Z.K. All authors have read and agreed to the published version of the manuscript.

Funding: This work was funded by Fundação de Amparo a Pesquisa do Estado de São PauloFAPESP (Grant\#17/25300-8). Glaucia Rigotto Caruso was supported by a master's fellowship from Coordenação de Aperfeiçoamento de Pessoal de Nível Superior—Brasil (CAPES)—Finance Code 001.

Data Availability Statement: Data is contained within the article or supplementary material.

Acknowledgments: The authors acknowledge Renata Fonseca Viana Lopez for DLS analyzes; Fernando Barbosa for ICP-MS analyzes; Luciano Bachmann for the 96-LED array; Tais Nader Chrysostomo Massaro for supporting in DLS, zeta and data analyzes.

Conflicts of Interest: The authors report nothing to disclose.

\section{References}

1. Pfaller, M.A. Antifungal Drug Resistance: Mechanisms, Epidemiology, and Consequences for Treatment. Am. J. Med. 2012, 125, S3-S13. [CrossRef] [PubMed]

2. Parker, J.E.; Warrilow, A.G.S.; Price, C.L.; Mullins, J.G.L.; Kelly, D.E.; Kelly, S.L. Resistance to antifungals that target CYP51. J. Chem. Biol. 2014, 7, 143-161. [CrossRef] [PubMed]

3. Kordalewska, M.; Zhao, Y.; Lockhart, S.R.; Chowdhary, A.; Berrio, I.; Perlin, D.S. Rapid and accurate molecular identification of the emerging multidrug-resistant pathogen Candida auris. J. Clin. Microbiol. 2017, 55, 2445-2452. [CrossRef]

4. Perlin, D.S.; Rautemaa-Richardson, R.; Alastruey-Izquierdo, A. The global problem of antifungal resistance: Prevalence, mechanisms, and management. Lancet Infect. Dis. 2017, 17, e383-e392. [CrossRef]

5. Freire, F.; Ferraresi, C.; Jorge, A.O.C.; Hamblin, M. Photodynamic therapy of oral Candida infection in a mouse model. Photodiagn. Photodyn. Ther. 2017, 17, A42. [CrossRef]

6. de Menezes, H.D.; Tonani, L.; Bachmann, L.; Wainwright, M.; Braga, G.Ú.L.; von Zeska Kress, M.R. Photodynamic treatment with phenothiazinium photosensitizers kills both ungerminated and germinated microconidia of the pathogenic fungi Fusarium oxysporum, Fusarium moniliforme and Fusarium solani. J. Photochem. Photobiol. B Biol. 2016, 164, 1-12. [CrossRef] [PubMed]

7. Wainwright, M.; McLean, A. Rational design of phenothiazinium derivatives and photoantimicrobial drug discovery. Dye Pigment. 2017, 136, 590-600. [CrossRef]

8. Castano, A.P.; Demidova, T.N.; Hamblin, M.R. Mechanisms in photodynamic therapy: Part one-Photosensitizers, photochemistry and cellular localization. Photodiagn. Photodyn. Ther. 2004, 1, 279-293. [CrossRef]

9. Misba, L.; Kulshrestha, S.; Khan, A.U. Antibiofilm action of a toluidine blue O-silver nanoparticle conjugate on Streptococcus mutans: A mechanism of type I photodynamic therapy. Biofouling 2016, 32, 313-328. [CrossRef]

10. Kaabipour, S.; Hemmati, S. A review on the green and sustainable synthesis of silver nanoparticles and one-dimensional silver nanostructures. Beilstein J. Nanotechnol 2021, 12, 102-136. [CrossRef]

11. Padnya, P.; Gorbachuk, V.; Stoikov, I. The Role of Calix[n]arenes and Pillar[n]arenes in the Design of Silver Nanoparticles: Self-Assembly and Application. Int. J. Mol. Sci. 2020, 21, 1425. [CrossRef] [PubMed]

12. Ahmad, S.; Munir, S.; Zeb, N.; Ullah, A.; Khan, B.; Ali, J.; Bilal, M.; Omer, M.; Alamzeb, M.; Salman, S.M.; et al. Green nanotechnology: A review on green synthesis of silver nanoparticles-An ecofriendly approach. Int. J. Nanomed. 2019, 14, 5087-5107. [CrossRef] [PubMed]

13. Keshari, A.K.; Srivastava, R.; Yadav, S.; Nath, G.; Gond, S.K. Synergistic activity of green silver nanoparticles with antibiotics. Nanomed. Res. J. 2020, 5, 44-54.

14. Alizadeh behbahani, B.; Noshad, M.; Falah, F. The combined effect of the combined Fennel and Clove essential oils on Staphylococcus epidermidis, Bacillus cereus, Salmonella typhi and Enterobacter aerogenes using Checkerboard assay (fractional inhibitory concentration index). Food Sci. Technol. 2020. [CrossRef] 
15. Rodrigues, G.B.; Dias-Baruffi, M.; Holman, N.; Wainwright, M.; Braga, G.U.L. In vitro photodynamic inactivation of Candida species and mouse fibroblasts with phenothiazinium photosensitisers and red light. Photodiagn. Photodyn. Ther. 2013, 10, 141-149. [CrossRef]

16. Idowu, M.; Nyokong, T. Photophysical and photochemical properties of zinc and aluminum phthalocyanines in the presence of magnetic fluid. J. Photochem. Photobiol. A Chem. 2007, 188, 200-206. [CrossRef]

17. Vankayala, R.; Kuo, C.L.; Sagadevan, A.; Chen, P.H.; Chiang, C.S.; Hwang, K.C. Morphology dependent photosensitization and formation of singlet oxygen $\left({ }^{1} \Delta \mathrm{g}\right)$ by gold and silver nanoparticles and its application in cancer treatment. J. Mater. Chem B 2013, 1, 4379-4387. [CrossRef] [PubMed]

18. Narband, N.; Tubby, S.; Parkin, I.; Gil-Tomas, J.; Ready, D.; Nair, S.; Wilson, M. Gold Nanoparticles Enhance the Toluidine Blue-Induced Lethal Photosensitisation of Staphylococcus aureus. Curr. Nanosci. 2008, 4, 409-414. [CrossRef]

19. Gil-Tomás, J.; Tubby, S.; Parkin, I.P.; Narband, N.; Dekker, L.; Nair, S.P.; Wilson, M.; Street, C. Lethal photosensitisation of Staphylococcus aureus using a toluidine blue O-tiopronin-gold nanoparticle conjugate. J. Mater. Chem. 2007, 17, 3739. [CrossRef]

20. Sherwani, M.A.; Tufail, S.; Khan, A.A.; Owais, M. Gold Nanoparticle-Photosensitizer Conjugate Based Photodynamic Inactivation of Biofilm Producing Cells: Potential for Treatment of C. albicans Infection in BALB/c Mice. PLoS ONE 2015, 10, e0131684. [CrossRef]

21. Ahmad, A.; Mukherjee, P.; Senapati, S.; Mandal, D.; Khan, M.I.; Kumar, R.; Sastry, M. Extracellular biosynthesis of silver nanoparticles using the fungus Fusarium oxysporum. Colloids Surf. B Biointerfaces 2003, 28, 313-318. [CrossRef]

22. Abbas, S.; Abadi, H.-N. Controlled Biosynthesis of Silver Nanoparticles Using Culture Supernatant of Filamentous Fungus. Iran. J. Chem. Chem. Eng. 2017, 36, 33-42.

23. Ishida, K.; Cipriano, T.F.; Rocha, G.M.; Weissmüller, G.; Gomes, F.; Miranda, K.; Rozental, S. Silver nanoparticle production by the fungus Fusarium oxysporum: Nanoparticle characterisation and analysis of antifungal activity against pathogenic yeasts. Mem. Inst. Oswaldo Cruz 2013, 109, 220-228. [CrossRef]

24. Durán, N.; Marcato, P.D.; Alves, O.L.; De Souza, G.I.; Esposito, E. Mechanistic aspects of biosynthesis of silver nanoparticles by several Fusarium oxysporum strains. J. Nanobiotechnol. 2005, 3, 8. [CrossRef]

25. Khandel, P.; Shahi, S.K. Mycogenic nanoparticles and their bio-prospective applications: Current status and future challenges. J. Nanostruct. Chem. 2018, 8, 369-391. [CrossRef]

26. Elagamey, E.; Narula, K.; Sinha, A.; Ghosh, S.; Abdellatef, M.A.E.; Chakraborty, N.; Chakraborty, S. Quantitative Extracellular Matrix Proteomics Suggests Cell Wall Reprogramming in Host-Specific Immunity during Vascular Wilt Caused by Fusarium oxysporum in Chickpea. Proteomics 2017. [CrossRef]

27. Schoffelmeer, E.A.M.; Vossen, J.H.; Van Doorn, A.A.; Cornelissen, B.J.C.; Haring, M.A. FEM1, a Fusarium oxysporum glycoprotein that is covalently linked to the cell wall matrix and is conserved in filamentous fungi. Mol. Gen. Genet. 2001, 265, 143-152.

28. Bansal, V.; Rautaray, D.; Ahmad, A.; Sastry, M. Biosynthesis of zirconia nanoparticles using the fungus Fusarium oxysporum. J. Mater. Chem. 2004, 14, 3303-3305. [CrossRef]

29. Bleackley, M.R.; Samuel, M.; Garcia-Ceron, D.; McKenna, J.A.; Lowe, R.G.T.; Pathan, M.; Zhao, K.; Ang, C.-S.; Mathivanan, S.; Anderson, M.A. Extracellular Vesicles From the Cotton Pathogen Fusarium oxysporum f. sp. vasinfectum Induce a Phytotoxic Response in Plants. Front. Plant Sci. 2020, 10, 1610. [CrossRef] [PubMed]

30. Baker, R.A.; Tatum, J.H. Novel anthraquinones from stationary cultures of Fusarium oxysporum. J. Ferment. Bioeng. 1998, 85, 359-361. [CrossRef]

31. da Rosa-Garzon, N.G.; Laure, H.J.; Rosa, J.C.; Cabral, H. Fusarium oxysporum cultured with complex nitrogen sources can degrade agricultural residues: Evidence from analysis of secreted enzymes and intracellular proteome. Renew. Energy 2019, 133, 941-950. [CrossRef]

32. Rodríguez-León, E.; Iñiguez-Palomares, R.; Navarro, R.; Herrera-Urbina, R.; Tánori, J.; Iñiguez-Palomares, C.; Maldonado, A. Synthesis of silver nanoparticles using reducing agents obtained from natural sources (Rumex hymenosepalus extracts). Nanoscale Res. Lett. 2013, 8, 318. [CrossRef] [PubMed]

33. Makama, S.; Kloet, S.K.; Piella, J.; van den Berg, H.; de Ruijter, N.C.A.; Puntes, V.F.; Rietjens, I.M.C.M.; van den Brink, N.W. Effects of Systematic Variation in Size and Surface Coating of Silver Nanoparticles on Their In Vitro Toxicity to Macrophage RAW 264.7 Cells. Toxicol. Sci. 2018, 162, 79-88. [CrossRef]

34. Mie, G. Contributions to the Optics of Turbid Media: Particularly of Colloidal Metal Solutions; H.M.S.O.: London, UK, 1976.

35. DurÁn, N.; Marcato, P.D.; Ingle, A.; Gade, A.; Rai, M. Fungi-Mediated Synthesis of Silver Nanoparticles: Characterization Processes and Applications. In Progress in Mycology; Springer: Dordrecht, The Netherlands, 2010; pp. 425-449.

36. Pabisch, S.; Feichtenschlager, B.; Kickelbick, G.; Peterlik, H. Effect of interparticle interactions on size determination of zirconia and silica based systems-A comparison of SAXS, DLS, BET, XRD and TEM. Chem. Phys. Lett. 2012, 521, 91-97. [CrossRef]

37. Marcato, P.D.; Durán, M.; Huber, S.; Rai, M.; Melo, P.S.; Alves, O.L.; Durán, N. Biogenic silver nanoparticles and its antifungal activity as a new topical transungual drug. J. Nano Res. 2012, 20, 99-107. [CrossRef]

38. Marcato, P.D.; De Paula, L.B.; Melo, P.S.; Ferreira, I.R.; Almeida, A.B.A.; Torsoni, A.S.; Alves, O.L. In vivo evaluation of complex biogenic silver nanoparticle and enoxaparin in wound healing. J. Nanomater. 2015. [CrossRef]

39. Birla, S.S.; Gaikwad, S.C.; Gade, A.K.; Rai, M.K. Rapid Synthesis of Silver Nanoparticles from Fusarium oxysporum by Optimizing Physicocultural Conditions. Sci. World J. 2013. [CrossRef] 
40. Gaikwad, S.C.; Birla, S.S.; Ingle, A.P.; Gade, A.K.; Marcato, P.D.; Rai, M.; Duran, N. Screening of different Fusarium species to select potential species for the synthesis of silver nanoparticles. J. Braz. Chem. Soc. 2013, 24, 1974-1982.

41. Van Dong, P.; Ha, C.H.; Binh, L.T.; Kasbohm, J. Chemical synthesis and antibacterial activity of novel-shaped silver nanoparticles. Int. Nano Lett. 2012, 2, 9. [CrossRef]

42. Sharma, V.K.; Yngard, R.A.; Lin, Y. Silver nanoparticles: Green synthesis and their antimicrobial activities. Adv. Colloid Interface Sci. 2009, 145, 83-96. [CrossRef]

43. Picoli, S.U.; Durán, M.; Andrade, P.F.; Duran, N. Research Article Frontiers in Nanoscience and Nanotechnology Front. Nanosci. Nanotechnol. 2016, 2, 107-110.

44. Du, L.; Xu, Q.; Huang, M.; Xian, L.; Feng, J.-X. Synthesis of small silver nanoparticles under light radiation by fungus Penicillium oxalicum and its application for the catalytic reduction of methylene blue. Mater. Chem. Phys. 2015, 160, 40-47. [CrossRef]

45. Soleimani, F.F.; Saleh, T.; Shojaosadati, S.A.; Poursalehi, R. Green Synthesis of Different Shapes of Silver Nanostructures and Evaluation of Their Antibacterial and Cytotoxic Activity. Bionanoscience 2018, 8, 72-80. [CrossRef]

46. Kitching, H.; Kenyon, A.J.; Parkin, I.P. The interaction of gold and silver nanoparticles with a range of anionic and cationic dyes. Phys. Chem. Chem. Phys. 2014, 16, 6050-6059. [CrossRef]

47. Longhi, C.; Santos, J.P.; Morey, A.T.; Marcato, P.D.; Durán, N.; Pinge-Filho, P.; Nakazato, G.; Yamada-Ogatta, S.F.; Yamauchi, L.M. Combination of fluconazole with silver nanoparticles produced by Fusarium oxysporum improves antifungal effect against planktonic cells and biofilm of drug-resistant Candida albicans. Med. Mycol. 2016, 54, 428-432. [CrossRef]

48. Kim, K.-J.; Sung, W.S.; Suh, B.K.; Moon, S.-K.; Choi, J.-S.; Kim, J.G.; Lee, D.G. Antifungal activity and mode of action of silver nano-particles on Candida albicans. BioMetals 2009, 22, 235-242. [CrossRef] [PubMed]

49. Hwang, I.; Lee, J.; Hwang, J.H.; Kim, K.-J.; Lee, D.G. Silver nanoparticles induce apoptotic cell death in Candida albicans through the increase of hydroxyl radicals. FEBS J. 2012, 279, 1327-1338. [CrossRef]

50. Paziani, M.H.; Tonani, L.; de Menezes, H.D.; Bachmann, L.; Wainwright, M.; Braga, G.Ú.L.; von Zeska Kress, M.R. Antimicrobial photodynamic therapy with phenothiazinium photosensitizers in non-vertebrate model Galleria mellonella infected with Fusarium keratoplasticum and Fusarium moniliforme. Photodiagn. Photodyn. Ther. 2019, 25, 197-203. [CrossRef]

51. Rodrigues, G.B.; Primo, F.L.; Tedesco, A.C.; Braga, G.U.L. In Vitro Photodynamic Inactivation of Cryptococcus neoformans Melanized Cells with Chloroaluminum Phthalocyanine Nanoemulsion. Photochem. Photobiol. 2012, 88, 440-447. [CrossRef]

52. de Menezes, H.D.; Rodrigues, G.B.; de Teixeira, S.P.; Massola, N.S.; Bachmann, L.; Wainwright, M.; Braga, G.U.L. In vitro photodynamic inactivation of plant-pathogenic fungi Colletotrichum acutatum and Colletotrichum gloeosporioides with Novel Phenothiazinium photosensitizers. Appl. Environ. Microbiol. 2014, 80, 1623-1632. [CrossRef]

53. Hone, D.C.; Walker, P.I.; Evans-Gowing, R.; Fitzgerald, S.; Beeby, A.; Chambrier, I.; Cook, M.J.; Russell, D.A. Generation of Cytotoxic Singlet Oxygen via Phthalocyanine-Stabilized Gold Nanoparticles: A Potential Delivery Vehicle for Photodynamic Therapy. Langmuir 2002, 18, 2985-2987. [CrossRef]

54. Ding, R.; Yu, X.; Wang, P.; Zhang, J.; Zhou, Y.; Cao, X.; Tang, H.; Ayres, N.; Zhang, P. Hybrid photosensitizer based on amphiphilic block copolymer stabilized silver nanoparticles for highly efficient photodynamic inactivation of bacteria. RSC Adv. 2016, 6, 20392-20398. [CrossRef]

55. Khan, S.; Alam, F.; Azam, A.; Khan, A.U. Gold nanoparticles enhance methylene blue-induced photodynamic therapy: A novel therapeutic approach to inhibit Candida albicans biofilm. Int. J. Nanomed. 2012, 7, 3245-3257. [CrossRef]

56. Ramarao, N.; Nielsen-Leroux, C.; Lereclus, D. The insect Galleria mellonella as a powerful infection model to investigate bacterial pathogenesis. J. Vis. Exp. 2012. [CrossRef]

57. Fuchs, B.B.; O’Brien, E.; Khoury, J.B.E.; Mylonakis, E. Methods for using Galleria mellonella as a model host to study fungal pathogenesis. Virulence 2010, 1, 475-482. [CrossRef] [PubMed]

58. Mylonakis, E.; Moreno, R.; El Khoury, J.B.; Idnurm, A.; Heitman, J.; Calderwood, S.B.; Ausubel, F.M.; Diener, A. Galleria mellonella as a model system to study Cryptococcus neoformans pathogenesis. Infect. Immun. 2005, 73, 3842-3850. [CrossRef]

59. Brennan, M.; Thomas, D.Y.; Whiteway, M.; Kavanagh, K. Correlation between virulence of Candida albicans mutants in mice and Galleria mellonella larvae. FEMS Immunol. Med. Microbiol. 2002, 34, 153-157. [CrossRef]

60. Ignasiak, K.; Maxwell, A. Galleria mellonella (greater wax moth) larvae as a model for antibiotic susceptibility testing and acute toxicity trials. BMC Res. Notes 2017. [CrossRef] [PubMed] 